\title{
An Investigation into the Language and Generalization Abilities in the Brain-injured and Non Brain-injured Mentally Retarded Child
}

\author{
ILANA OKEN
}

\section{Introduction and Aims}

J. L. Khanna in his book "Brain Damage and Mental Retardation" reports a study by Mednick and Wild in which they found that the brain-injured child has a diminished degree of generalization responsiveness. (1968, 9.) It would seem that if a child has difficulty with generalization, he should also have difficulty in language development where a word must come to stand for an action or an object in many different situations and contexts.

One of the most salient features of the mentally retarded child is his impoverished verbal behaviour, i.e. his delayed and impaired language. $(1964,18$.) Luria regards the basic symptom of the mentally retarded child, or the oligophrenic child as he terms it, as a profound disturbance in the operations of abstraction and generalization which manifests itself in, and dominates the whole of cognitive functioning. $(1963,11$.

In terms of the above the writer felt that it would be interesting to conduct a comparative study of two groups of mentally retarded children, one of them brain-injured, the other non brain-injured, to see if there is any relationship between the differences in their language and generalization abilities, for if there is, this could be of great therapeutic and prognostic value.

Goldstein has described the brain-damaged adult as being deficient in the use of the "abstract attitude". Perhaps this, as well as the concept of "rigidity" in the brain-injured child's thinking as postulated by Goldstein, Werner and others $(1954,13)(1966,6)$ can be viewed as a diminished generalization ability, and these ideas have led the writer to investigate this field in the brain-injured child.

Most of the research on the language of the retarded is confined primarily to the study of speech. The research that is' cited on the "language" of mentally retarded children tends to reveal only that these children are defective on various measures of language without actually describing retarded children's language pattern. In using the Illinois Test of Psycholinguistic Abilities, (the ITPA), the writer attempted to describe various areas of strengths and weaknesses within the two samples of retarded children, investigating:

(i) Whether the frequently stated assumption that the brain-injured child has a "peaked profile" and that the mentally retarded child has 
a "relatively flat profile" exists, and whether this differentiation exists in the language abilities of the two diagnostic groups;

(ii) whether retarded children differ psycholinguistically from average children of comparable mental age;

(iii) whether there is a "typical" profile for the brain-injured mentally retarded and the non brain-injured mentally retarded.

The writer was unable to find any test of generalization which could be used (other than complex equipment involving machinery) and, therefore, thought that it would be advantageous to devise a simple test which could be used diagnostically, therapeutically and prognostically.

The writer views generalization as the grouping together of stimuli or objects which are similar, but not identical, to form a class, a category or a concept. Parsins, Skill et al state that this process is "the categorization of the particular, concrete objects of his situation into classes". $(1955,20$.) Hubert Alexander clearly differentiated abstraction from generalization. He says that these processes are the reverse of each other, for generalization is the process of grouping like units together into classes, whereas abstracting is a process of selecting out attributes by focusing upon them. $(1967,1$.) However, the writer feels that generalization involves abstracting to the extent that objects or events are grouped together by virtue of the certain abstractable traits which they have in common. Rosenstein feels that concept formation is a progression from perception, to abstraction to generalization. $\mathrm{He}$ feels that concept formation is dependent on abstraction, and that concept utilization on generalization. $(1961,15).(1963,16$.

Strauss and Kephart regard generalization as being essential in the development of concepts. They feel that generalization first occurs on a perceptual level, where the child makes perceptual responses to his object world by classifying, e.g. four cornered figures are classified as "squares" irrespective of their size, colour, whether they are solid figures or outline shapes. This is generalization of shape. As the child develops, a transition occurs from the perceptual generalizations to generalization over a less immediate or direct route. Categorizations are now made according to function, use, location and later according to higher level groupings. $(1955,20$.)

The basic theme of the book "A Study of Thinking" by Bruner, Goodnow and Austin is that virtually all cognitive activity is dependent on the process of categorizing. $(1957,5$.) Bruner developed this theme further by emphasizing that the development of a language system is a prerequisite to making generalizations beyond immediate environ- mental situations. $(1966,8$.) Rosenstein also feels that the development of concepts is greatly aided by language and other symbols. $(1963,16$.

Many learning theorists have differentiated between primary and secondary stimulus generalization. Irv Bialer defines primary stimulus generalization as "a response to superficial sensory similarity of stimuli which have been given otherwise distinctive characteristics in the form

Tydskrif van die Suid-Afrikaanse Logopediese Vereniging, Vol. 17, Nr. 1: Des. 1970 
of different labels". He says that in secondary stimulus generalization the utilization of learned equivalence is required. $(1961,4$.) Leventhal says that categorization is assumed to be on a perceptual level in the case of primary stimulus generalization and on a conceptual level in the case of secondary stimulus generalization. He distinguishes between perception and conception in terms of:

1. Speed and locus of action. Perception operates quickly and refers to objects present in the environment. Conception operates more slowly on the basis of symbolic, non-sensory bound cues.

2. Susceptibility to the influence of irrelevant and redundant information. Perception is more greatly influenced by these than is conception.

Vygotsky views the formation of concepts as a developmental sequence of generalizations, at first grouping syncretic heaps together, i.e. with no apparent principle in mind, then progressing to a higher level of generalization where he groups according to unique associations, e.g. toys "belong" in his playpen, he then proceeds to group according to some functional relationship, and the epitome of categorization in Vygotsky's system occurs with the mastering of the superordinate. $(1962,22).(1967,19$.

\section{Experimental Methodology}

1. Subjects: Ten subjects were used in this study. Five of these children formed the brain-injured group, and the other five the non brain-injured group. All the subjects were mentally retarded and enrolled in special classes in Government schools in Johannesburg. For the purpose of classifying the subjects into the two experimental groups, the writer used a combination of the Riggs and Rain classification system $(1952,14)$ and the system proposed by Schulman, Kaspar and Throne. $(1965,17$.$) The criteria for selection into the "brain-injured" group$ are some of those laid down for the Riggs and Rain "organic" group, and the "non brain-injured" group are equivalent to Schulman et al group 2, i.e. "patients at the low end of the normal distribution curve". Four out of the five subjects in the non brain-injured group fit into the Riggs and Rain group of "unexplained", i.e. children who, in spite of fairly detailed case histories, can be called neither familial nor organic without resorting to inference rather than to fact. The fifth child's retardation is of the familial type.

(a) Brain-injured group: The subjects used in this group were selected in terms of meeting with one of the following criteria:

(i) Diagnosis of brain-injury by a neurologist;

(ii) case history indicating anoxia at birth;

(iii) encephalitis before baby aged six months;

(iv) epilepsy diagnosed medically:

Three of the subjects had been diagnosed as brain-injured by neurologists. B5 had hemiparesis on the right side, B4 had frequent grand 
mal epileptic attacks and B2 had nystagmus in the right eye. The case histories of B1 and B3 indicate anoxia at birth. B4 had encephalitis at two weeks, which was followed by the epileptic attacks, and B5 was the second of a stillborn twin, weighed $1 \frac{1}{2}$ pounds at birth, suffered from anoxia at birth and was given a transfusion immediately after birth.

(b) Non brain-injured group: The children in this group were selected in terms of the following criteria:

(i) No organic cause present in the case history;

(ii) no organic symptomatology present;

(iii) these children were diagnosed as mentally retarded on the basis of an intelligence test.

(c) Intelligence: Before a child is admitted to a special class in a Government school, he has to be assessed by the school psychologist. The child's intelligence is tested on the South African Individual Scale. Thus the intelligence of all the children was tested on the same scale, and all the tests were done after January 1968. The IQ scores of the subjects ranged from 65 to 80 .

(d) Socio-economic class: Four of the subjects were at Gresswold School and the other six were in the "coaching class" at Emmarentia Primary School. Both schools are in the northern suburbs of Johannesburg, and all the children were of middle-class parents. None of the children were, or had ever been institutionalized; all children lived at home.

(e) Chronological age: The chronological ages of the children ranged between 7 and 11 years. Because of difficulties in getting children of the same chronological age (CA) and IQ, the subjects were matched in pairs as closely as possible with respect to $\mathrm{CA}$, IQ and sex where possible.

(f) Further criteria for selection were:

(i) The subjects had to be ambulatory and have sufficient motor coordination to carry out the tasks, e.g. pointing, picking up blocks;

(ii) children with severe personality and emotional problems were not used; however, some of the children in the brain-injured group did show some of the "Strauss-type" behaviour symptoms, but none of these problems was severe;

(iii) the children had to be able to express their basic needs and understand simple directions;

(iv) the children had to be able to differentiate shapes of a triangle, circle and square. They had to be able to post the appropriate shape in the "post box" task;

(v) the teachers of the children reported that none of the children had difficulty with colour perception, and none had any hearing difficulty.

\section{Procedure:}

(a) Conditions for the experiment: The environment in which the experiment was carried out was familiar to all the children. Eight 
of the children were tested at their schools, and they were taken out of their regular class one at a time and were tested in a classroom at the far end of the school. The situation was controlled as far as possible for both extraneous auditory and visual stimuli. The two children not tested at school were tested at their homes, at a table in a quiet room.

(b) The tests administered were:

I. The ITPA.

II. A generalization test devised by the writer which was administered following a pause of five minutes after the completion of the ITPA.

(c) Standardization of the Generalization Test:

The generalization test was given to 12 "normal" children aged between $3 \frac{1}{2}$ and 7 years. These 12 children formed the standardization group. They lived in either Gresswold or Emmarentia, and were, therefore, children of the same socio-economic class as the subjects in the experimental groups. The purpose of giving this test to the normal children was to roughly standardize the test, to get an idea as to how normal children would perform on this test so as to be able to compare the performance of the experimental groups with the normal group.

\section{Materials:}

I. The ITPA: This is a diagnostic test of language abilities. It is a battery of nine subtests, each subtest assessing a particular aspect of the global area of language ability. The ITPA was administered in the recommended order and in accordance with the instructions laid out in the manual. $(1961,12$.) The only exception was a five-minute pause after the visual-motor sequencing subtest. This pause was given to all subjects, as the writer felt that the test was a long one, and that the pause would overcome, to a certain extent, the element of fatigue.

\section{The Generalization Test:}

(a) Theoretical framework on which the Generalization Test is based:

Generalization or categorization, as has been shown by several authorities (Strauss and Kephart, Rosenstein, Vygotsky and others) is a developmental phenomenon, and proceeds from the concrete perceptual to the more complex conceptual mode. The child at first operates on the basis of superficial, sensory bound cues and groups according to what he "sees" and what "is". He then proceeds to group according to more conceptual aspects, not to what "is" in the present, but according to less stimulus bound and more symbolic cues. He now begins to group dissimilar looking cues into one group and regards them as being "the same" in terms of their functions, uses, lccations, etc.

The test is, therefore, divided into three levels, all increasing in complexity.

There are three pretest items, the purpose of which is to illustrate to the child that he must group items together that constitute one category, e.g. "squares". 
Section 1 of the test involves grouping together of blocks of different sizes, shapes and, later, colours into particular categories. Here the child is required to generalize in terms of the objects he sees before him-this is on a concrete perceptual level.

Section 2 of the test involves the child choosing one picture out of three that can be grouped with three other pictures, all of one category or stimulus class. Here the child is required to form the generalization in terms of the picture that he sees.

Section 3 requires the child to select one word out of four that does not fit into the category. Here the child is required to generalize three of the words into a category or higher level concept, and verbalize the word that does not fit into the desired category.

Each item of every subtest is graded in difficulty, and thus it is expected that a child who fails item (d) in the first section of the test will not pass items in the second section of the test.

(b) Description of the Generalization Test:

Pretest: In this part of the test, nine blocks are used, three identical squares, three identical triangles and three identical circles. They are identical with respect to colour, size and shape.

(a)
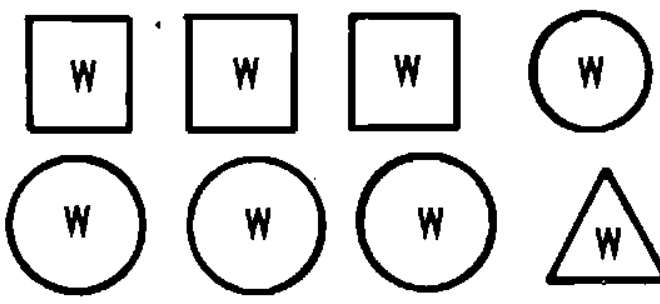

(b)
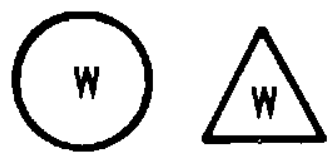

(c)
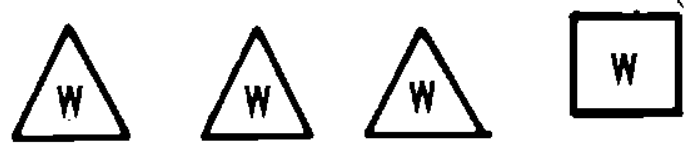

$$
W=\text { White }
$$

The three squares and the circle are placed in front of the child and the child is instructed to place all the blocks that are "the same" into the tester's hand. If the child succesfully completes item (a) by himself, the same procedure is carried out for pretest items (b) and (c). If the child fails item (a), the tester shows the child how to succesfully complete the task, and explains to the child that the three squares are the same because they all look alike, all have four sides and all are "squares". The child is then given item (b) to do. If the child fails item (b), he is again shown how to successfully complete the task, and the tester explains the reasons for the grouping. The child is then given item (c). Should he fail this item, the test is then stopped. 
Section 1: In this section, blocks of various sizes, shapes and colours are used, and the child has to group those objects that are the "same". Sameness of shape is the type of grouping required. The five items are:

(a)
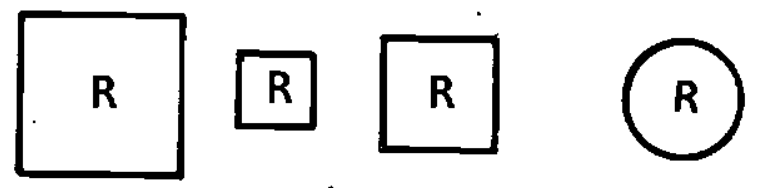

(b)
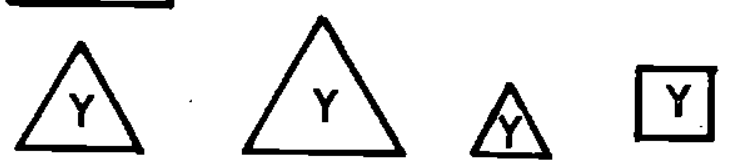

(c)
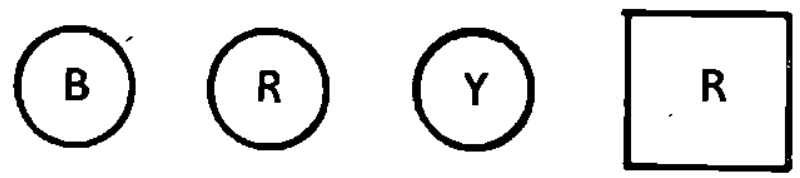

(d)
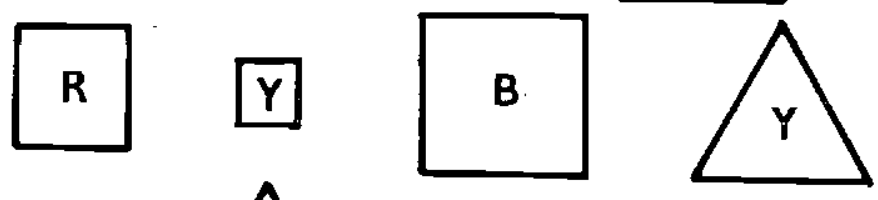

(e)
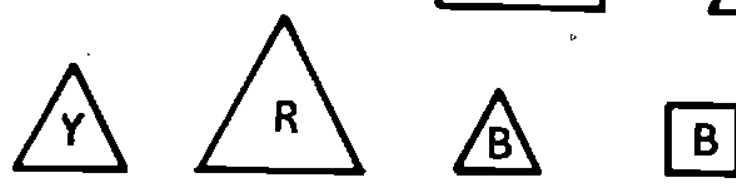

$$
\mathbf{R}=\mathbf{R e d}
$$

$$
\mathbf{B}=\text { Blue } \mathbf{Y}=\text { Yellow }
$$

Blocks for'item (a) are randomly placed on the table before the child. The child is again instructed to place those blocks that are "the same" into the tester's hand. If the child is able to do this without assistance, the test is continued in the same manner. If the child is unable to do the item, or groups according to colour, the tester shows the child the correct way of grouping. The child is then given item (b) to do; if the child fails to do this correctly, the tester again shows and explains the correct grouping; if the child then fails item (c), the test is stopped.

Section 2: In this part of the test, white cards $2 \frac{1}{2}$ inches by $3 \frac{1}{2}$ inches with clear pictures pasted on them are used. The child is required to group pictures together that are of the same category. The following categories are used: (a) animals; (b) furniture; (c) people; (d) parts of the face; (e) jewellery. Before commencing the test, the tester explains to the child which is the "top row" and which is the "bottom row". The child is then required to indicate which row is which on command. The child is then instructed to show the tester which card on the bottom row is "the same as, the same thing as, goes with" the 
three cards in the top row. The instructions are given to the child in these three ways to ensure that he understands what is required of him. If the child completes the item successfully, the test is continued in the same manner. If the child fails item (a) the tester shows the child the correct way of grouping, explaining that they are all of one category, e.g. animals, and the child is then given item (b) to do, and the same procedure is followed as that in section 1.

The cards used in this section of the test are placed on the table in the following order :
(a) 1. elephant
2. cat
3. horse
4. $\operatorname{dog}$
5. boy
6. car
(b) 1. cupboard
2. chair
3. table
4. dress
5. bed
6. flower
(c) 1. mother
2. boy
3. father
4. $\operatorname{dog}$
5. girl
6. table
(d) 1. eyes
2. ears
3. mouth
4. nose
5. apple
6. dress
(e) 1. brooch
2. watch
3. necklace
4. chair
5. girl
6. ring

Section 3: This section has an example given to the child first to explain what is required of him, and five items then follow. In the example item the words "dog, cow, ball, pig" are given and, if the child responds correctly, the test is continued as in sections 1 and 2 . If the child fails to give the correct response, the tester explains to the child why "ball" is the word that does not fit. The child is then given item (a) to do and, if he fails, he is given the correct response and an explanation as to the reason. If the child then fails item (b), the test is stopped.

The series of words used in this section of the test are:
(a) hat
boat
(b) $\mathrm{car}$
train
shoes
coat
(c) fork
banana
ship
mountain
(d) river
sea
apple
grape
(e) lamp
sand
light
ball
swimming-pool

(c) General points in the administration of the test:

1. After three successive failures in any part of the test the test was stopped.

2. After each failure the child was shown the correct response.

3. When the child performed correctly, the tester acknowledged this by saying "good, that's right".

4. After each item in all sections of the test, the tester asked the child why he had grouped the objects, pictures or words in the way that he had, and the child's verbal responses were recorded.

(d) Scoring of the Generalization Test:

Every item of the test was weighted with a score one more than the score preceding it. Thus passing item (a) yielded a score of 1 , passing item (b) yielded a score $1+2$, i.e. 3 , passing item (c) yielded 
a score of 6 , i.e. $1+2+3$. The total number of points in the test was 120.

\section{Results}

\section{The ITPA:}

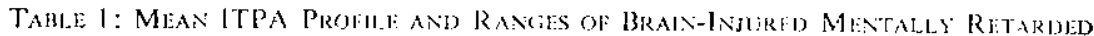
Grolis

\begin{tabular}{|c|c|c|c|c|c|c|c|c|c|}
\hline & \multicolumn{6}{|c|}{ Represemational Lerel } & \multicolumn{3}{|c|}{ Altom-Scanemial } \\
\hline & \multicolumn{2}{|c|}{ Decosing } & \multicolumn{2}{|c|}{ Assonciation } & \multicolumn{2}{|c|}{ Encoding } & fluthm. & \multicolumn{2}{|c|}{ Sequemial } \\
\hline & 1 & 2 & 3 & 4 & 5 & 6 & 7 & 8 & 9) \\
\hline & Alwh. & Vistal & $\begin{array}{l}\text { Alatl. } \\
\text { Vocat }\end{array}$ & $\begin{array}{l}\text { Vinwal } \\
\text { Motor }\end{array}$ & Fucal & Nolow & $\begin{array}{l}\text { ludel } \\
\text { lincal }\end{array}$ & $\begin{array}{l}\text { lud. } \\
\text { linted }\end{array}$ & $\begin{array}{l}\text { lisual } \\
\text { Wofor }\end{array}$ \\
\hline$+3 \cdot 00^{\circ}$ & & & & & & & & & \\
\hline$-2 \cdot 50$ & & & & & & & & & \\
\hline$\div 2 \cdot 00$ & & & & & & & & & \\
\hline$-1 \cdot 50$ & & & & & & & & & \\
\hline$+1 \cdot 00$ & & & & & & & & & \\
\hline$+\cdot 50$ & & & & & & & & & \\
\hline 00 & & & & & & & & & \\
\hline$-\cdot 50$ & & & & & & & & & \\
\hline$-1 \cdot 00$ & & & & & & & & & \\
\hline$-1 \cdot 50$ & & I & & & & & & & I \\
\hline $2 \cdot 00$ & & & & & & & & & \\
\hline$-2 \cdot 50$ & & & & & & & & & \\
\hline$-3 \cdot 00$ & & & & & & & & • & \\
\hline
\end{tabular}

The total language age scores of the two groups did not yield significant differences between the two groups, yet as can be seen from the above profiles the two diagnostic groups performanceś differ. Both groups have "peaked profiles" but these profiles are peaked in different areas, i.e. the groups show different strengths and weaknesses on the various subtests.

The brain-injured groups performance on visual subtests was inferior to its performance on auditory subtests on all levels. When this result was subjected to statistical analysis it was found to be significant at the ,001 level of confidence. The non brain-injured groups performance was poorer in the auditory channel for all subtests except auditory-vocal 
Tabre 2: Mfan ITPa Proflle and Ranges of Non Braln-líjulzed MrNtalli RETARdio Grous.

\begin{tabular}{|c|c|c|c|c|c|c|c|c|c|}
\hline \multirow[b]{5}{*}{$+3 \cdot 00$} & \multicolumn{6}{|c|}{ Representational Level } & \multicolumn{3}{|c|}{ Aurom-Sequential } \\
\hline & \multicolumn{2}{|c|}{ Decoting } & \multicolumn{2}{|c|}{ Association } & \multicolumn{2}{|c|}{ Encodingr } & \multirow{3}{*}{$\begin{array}{c}\text { tutom. } \\
7 \\
\text { Auded } \\
\text { Vocal }\end{array}$} & \multicolumn{2}{|c|}{ Senuential } \\
\hline & 1 & 2 & 3 & 4 & 5 & 6 & & 8 & 9 \\
\hline & Alud. & Visual & $\begin{array}{l}\text { Aud. } \\
\text { Voccal }\end{array}$ & $\begin{array}{l}\text { Viswal } \\
\text { Motor }\end{array}$ & Voral & Moror & & $\begin{array}{l}\text { Auth } \\
\text { Voẹt }\end{array}$ & $\begin{array}{l}\text { Visual } \\
\text { Moter }\end{array}$ \\
\hline & & & & & & & & & \\
\hline$+2 \cdot 50$ & & & & & & & & & \\
\hline$-2 \cdot 00$ & & & . & & & & & & \\
\hline$+1 \cdot 50$ & & & & & & & & & \\
\hline$+1 \cdot 00$ & & & & & & & & & \\
\hline$\div \cdot 50$ & , & & & & & & & & \\
\hline 00 & & & & & & & & 1 & \\
\hline-.50 & & & & & & I & & & \\
\hline$-1 \cdot 00$ & & 1 & & & & & & & 1 \\
\hline$-1 \cdot 50$ & & & & & & & 1 & & \\
\hline$-2 \cdot 00$ & & & & & & & & & \\
\hline $2 \cdot 50$ & & & & & I & & & & \\
\hline$-3 \cdot 00$ & & & & & & & & 1 & \\
\hline
\end{tabular}

sequencing. The result of this score was influenced by the extreme range in this subtest due to the heterogeneity in performance of the subjects in the group on this test. When the students $t$ test was applied to this result, the difference was not found to be statistically significant.

The non brain-injured group were statistically inferior to the braininjured group on the auditory-vocal automatic subtest at the ,02 level of significance.

The brain-injured group was inferior to the non brain-injured group in the whole decoding process, and thus although the non brain-injured group were poorer in their auditory as compared with their visual subtests, their performance on auditory decoding was superior to that of the brain-injured group. A t test was performed to see whether the difference between the groups performances on decoding and encoding were significant or not. The difference between the brain-injured groups encoding performance was not statistically significant, the non braininjured group were statistically superior to the brain-injured group in the decoding process at the, 001 level of confidence.

In both groups motor encoding was superior to vocal encoding. Both groups performed extremely poorly on both association subtests, the

Tydskrif van die Suid-Afrikaanse Logopediese Vereniging, Vol. 17, Nr. 1: Des. 1970 
brain-injured group were more inferior due to their deficit in the visual channel.

The range for each subtest was calculated. This is the difference between the uppermost and lowest scores on a particular subtest. It is interesting to observe the size of the ranges on the particular subtests. Most. of the subtests show fairly large ranges indicative of heterogenous performances by the subjects in the groups, however, both the association subtests have relatively small ranges indicating that all of the children in the two groups performed poorly on these subtests. It seems as though in this sample of brain-injured and non brain-injured mentally retarded children, all the children had difficulty in this area irrespective of their individual differences.

Within each diagnostic group a t test was performed to determine whether the groups abilities in encoding and decoding differed significantly. The difference between the brain-injured group's decoding and encoding abilities was significant at the ,001 level of confidence, and the difference between the non brain-injured group's decoding and encoding abilities was significant at the ,01 level.

When the mental ages of the subjects in both groups were compared with their language ages, it was found that these scores do not correlate well, but that there was a considerable difference between the two. The difference was found to be significant at the ,001 level of confidence.

\section{Results on Generalization Test:}

(a) Standardization group:

The following general trends in performance were observed:

(i) Children between $3 \frac{1}{2}$ and $4 \frac{1}{2}$ were able to complete all perceptual groupings and up to (d) of section 2. Thus their scores were approximately 45 .

(ii) Children between $4 \frac{1}{2}$ and $5 \frac{1}{2}$ were able to complete all perceptual and concrete conceptual groupings. They were able to complete up to section 3's (d), thus their scores were approximately 91.

(iii) Children over $5 \frac{1}{2}$ were able to complete the whole test successfully. Thus their scores were 120 .

(b) Experimental groups:

Table 3: Results on Generalization Test of the Brain-Injured AND NON BRAIN-INJURED GROUPS

\begin{tabular}{rr|r} 
& Brain-Injured & Non Brain-Injured \\
1. & 106 & 47 \\
2. & 15 & 105 \\
3. & 98 & 58 \\
4. & 37 & 0 \\
5. & 14 & 36 \\
Total: & $\frac{270}{54}$ & $\underline{246}$ \\
Mean: & $\overline{54} \cdot 2$ \\
\hline
\end{tabular}

Journal of the South African Logopedic Society, Vol. 17, No. 1: December 1970 
The brain-injured groups performance on this test was superior to the performance of the non brain-injured group, but when a $t$ test was performed on the above data it showed that the difference was not statistically significant. The reasons for the lack of significant results could be due to the following:

1. Small size of groups, and large range of possible scores.

2. Heterogeneity in performance of subjects closely matched for CA and IQ.

The subjects performance on this test was compared to the performance of normal-children in the standardization group. The generalization ability of both the brain-injured and non brain-injured groups appeared to be far inferior to their mental ages.

\section{Discussion}

From the findings of the present study one cannot emphatically state that there is a "typical" profile for the diagnostic groups, but it does seem that there are certain trends in performance of the two groups.

In the Gallagher study it was reported that there were tendencies for the brain-injured group to be superior to the non brain-injured group on items tapping the visual channel. $(1957,7$.$) In the present study the$ brain-injured group were significantly inferior in the visual channel for each process, but the deficit of the non brain-injured group in the auditory channel, though evident was not statistically significant. Strauss et al regard perceptual deficits as being characteristic of the brain-injured child. They say that "brain-injured children show a disintegration in the visual-perceptual field" (1947, 21.), and they use as their diagnostic tests of "brain-injury" tests of visual perception, e.g. the Werner-Strauss Marble Board. Bateman reports that children who show a visual motor disability on the ITPA are the children with "perceptual disorganization" or the "Strauss-syndrome" children. $(1965,2$.)

The deficit in the automatic sequential level which has been reported in the literature on the ITPA with mentally retarded children was evident in the non brain-injured group. Their performance was poor over the entire automatic-sequential level, but they showed the greatest deficit on this level in the auditory-vocal automatic subtest. The writer wishes to postulate that the poor performance on this subtest is related to their deficient generalization ability indicated on the generalization test. When children learn the grammar of their language they are not formally taught these rules. They hear different grammatical structures in their environment and from this they formulate a rule which they have to generalize in order to produce novel utterances. However they do not hear a rule in one way, but in a number of ways, i.e. in a number of different utterances all obeying that rule, and they have to automatically generalize the rule which they have learnt in situation A to situation B. Therefore a child who is deficient in his generalization ability will be deficient in a subtest tapping his ability to learn grammatical rules automatically. 
The greatest deficit in both diagnostic groups was in the association process. Bateman and Wetherell report that the type of association process assessed by the ITPA can be considered either as a retrieval or organization and generalization stage. They feel that it is impossible to determine on an auditory-vocal association deficit alone whether the problem is one of retrieval or organization and generalization. However they feel that the visual-motor association subtest is more heavily weighted with organization. $(1965,3$.) Since both groups in this study performed poorly on both the association subtests, the writer feels that these two tests are both tapping generalization ability.

In the performance of the subjects on the generalization test it was interesting to observe the manner in which the children of the different groups made their generalizations. Some of the responses of the braininjured children were bizarre and unrelated to the stimulus presentations particularly in section 2 of the test. In this section some of the braininjured children tended to make their groupings according to an association between one of the pictures in the bottom row and one of the pictures in the top row, e.g. boy and horse cause "boy sits on a horse". These associations tended to be on the basis of contiguity as in the above example, or activity between the two objects, e.g. boy and horse cause they both "go".

An interesting observation was the clear difference between grouping or generalizing on the perceptual and conceptual levels. Subjects B3, B4 and B5 experienced no difficulty in section 1, yet were unable to do the items in section 2. The performance of these subjects on the association subtest was their most inferior performance. Subject M4 had no difficulty in doing the pretest items, yet was unable to group stimuli differing in one respect, i.e. size. The subject showed the poorest generalization ability on the generalization test, and his ITPA scores showed the poorest deficits on auditory-vocal and auditory-vocal automatic subtests.

An important factor in generalization ability seemed to be the verbalization accompanying the grouping. The most successful subjects were those who were able to give the name of the category they were grouping, and it seemed as though appropriate use of verbal activity was the important factor, yet the subjects who merely named the picture they selected, e.g. "cause it's a dog" were more successful than those subjects who made no verbalizations. This point seems to illustrate Luria's thesis of speech regulating behaviour and also Strauss and Kephart's idea that the use of the category word unifies perceptions and later conceptions.

The findings of this study support the use of the ITPA as a diagnostic tool. The writer does not feel that a diagnosis can be made from the results on this test alone, but analysis of the profile can point in the direction of a particular diagnosis. Knowledge of etiology seems to be important as it indicates the type of therapy programme to be used. If the child is found to be brain-injured, the therapy or remediation 
prograrifme should stress the auditory avenue, i.e. an auditory approach to language training, as the stronger avenue can be used to facilitate the weaker.

Bateman and Wetherell feel that an important implication in the education of retarded children can be derived from the knowledge of a deficit in automatic rote aspects of language usage. The need for repetition, over learning and drills seems obvious, yet by making all learning situations meaningful to the child the retarded child will handle these tasks exclusively at the representational level, thus further strengthening his already relatively strong representational skills and neglecting the automatic-sequential abilities which are in need of exercise. $(1965,3$.)

Because the performance of both groups of children is deficient in the association process of the ITPA, therapy and education for the retarded child should place a direct emphasis on the formation of concepts, abstractions and generalizations.

The generalization test as it stands can be used prognostically, as, the child who performs superiorly on it should be more successful in therapy and achieve more in a shorter period of time than a child who shows poor generalization ability, as he will form concepts and thus learn language quicker.

The generalization test as it stands or modifications of it can be used therapeutically to train children in generalization. The performance of the child on the generalization test can also be a valuable therapeutic guide indicating from what point to begin therapy, whether one need work on a very concrete perceptual level or on a more conceptual level.

\section{Conclusions}

The total language age scores of the two groups did not yield significant differences between the two groups. However, when the performance of the two groups were broken down and analysed significant differences in areas of strengths and weaknesses were observed.

Both groups performed most inferiorly on the association subtests of the ITPA, and this performance correlated well with the poor performance of the subjects on the generalization test. The writer feels that there is a close inter-relationship between language ability and generalization ability, and this illustrates the importance of giving the child certain forms of non-language or perceptual training before beginning language therapy as it has been shown that these pre-language training procedures form the basis for conceptual development.

\section{Summary}

Five brain-injured children were compared with five non brain-injured children on the ITPA and a Generalization Test devised by the writer. These children were aged between 7 and 11 years, and their IQ scores 
were between 65 and 80 . All the children were in special chasses in government schools in Johannesburg, and were free of auditory, visual and physical disabilities. The results of this investigation were presented and discussed in terms of whether any difference in language ability of the subjects in this study was present, so as to see whether there was a "typical" profile for each diagnostic group. It was concluded that there are different types of peaks in the profiles of the two groups, and that both groups have poor generalization ability. A close inter-relationship between language and generalization abilities was considered to exist.

\section{Opsomming}

Vyf kinders met breinbesering is vergelyk mel vyf kinders sonder breinbesering deur middel van die ITPA en 'n veralgemeningstoets wat deur die skrywer opgestel is. Die kinders se ouderdomme was tussen 7 en 11 jaar, en hulle IK's tussen 65 en 80 . Alle kinders woon spesiale klasse in Staatskole in Johannesburg by, en was sonder gehoor, gesigs en fisiese gebreke. Die resultate van hierdie ondersoek was bespreek in terme van die moontlike verskil in talvermoë van die twee groepe. Daar was gepoog om te sien of daar wel 'n profiele was wat "tiperend" is van elke diagnostiese groep.

Die afleiding is gemaak dat daar verskillende soorte pieke in die profiele van die twee groepe voorkom, en beide groepe het 'n swak veralgemeningsvermoë. Dit het geblyk dat daar 'n noue verband tussen taal en veralgemeningsvermoë was.

\section{References}

1. Alexander, H. G. (I967): Language and Thinking. D. von Nostrand Co., Inc., New York.

2. Bateman, B. (1965): "The Role of the Illinois Test of Psycholinguistic Abilities in Differential Diagnosis and Programme Planning." American Journal of Orthopsychiatry, 35, pp. 465-472.

3. Bateman, B. and Wetherell, J. (1965): "Psycholinguistic Aspects of Mental Retardation." Mentol Retardation, 3, 2, pp. 8-14.

4. Bialer, 1. (1961): "Primary and Secondary Stimulus Generalization as related to Intelligence Level." Journal of Experimental Psychology, 62, 4, pp. 395-402.

5. Bruner, J. S., Goodnow, J. J. and Austin, G. A. (1957): A Study of Thinking. John Wiley \& Sons, Inc., New York.

6. Copelowitz, L. B. (1966): "Perceptual and Conceptual Defects of the BrainInjured Child (Including the Cerebral Palsy)." Unpublished dissertation for the degree of B.A. Logopedics, University of the Witwatersrand.

7. Gallagher, J. J. (1957): "A Comparison of Brain-1njured and Non BrainInjured Mentally Retarded Children on Several Psychological Variables." Monographs of the Society for Research in Child Development, 22, 2, No. 65.

8. Hamilton, J. (1966): "Learning of a Generalized Response Class in Mentally Retarded Individuals." American Journal of Mental Deficiency, 71, I, pp. 100-108.

9. Khanna, J. L. (1968): Brain Damage and Mental Retardation. Charles C. Thomas. Springfield, Illinois, U.S.A.i

10. Leventhal, D. S. (1966): "A Study of the Roles of Perceptual and Conceptual Categorization." Dissertation abstracts, 27, 118, pp. 316-317. 
11. Luria, A. R. (1963): The Mentally Retarded Child. Pergamon Press, New York.

12. McCarthy, J. J. and Kirk, S.A. (1961): Mlinois Test of Psycholinguistic Abilities-Examiner's Manual. University of lllinois, Institute for Research on Exceptional Children, Urbana Illin.

13. McMurry, J. G. (1954): "Rigidity in Conceptual Thinking in Exogenous and Endogenous Mentally Retarded Children." Journal of Consulting Psychology, 18, 5, pp: 366-370.

14. Riggs, M. M. and Rain, M. E. (1952): "A Classification System for the Mentally Retarded." The Training School Bulletin. 49. pp. 75-84.

15. Rosenstein, J. (1961): "Perception, Cognition and I anguage in Deaf Children." Exceptional Children. .27, pp. 276-284.

16. Rosenstein, J. (1963): "Concept Development and Language Instruction." Exceptional Children. 30 , pp. 337-343.

17. Schulman, J. L., Kaspar, J. C. and Throne, F. M. (1965): Brain Damage and Behaviour. A Clinical Experimental Study. Charles C. Thomas. Springfield. Illinois.

18. Siegal, G. M. (1964): "Prevailing Concepts in Speech Research with Mentally Retarded Children." $A S H A$, 6, pp. 192-194.

19. Silverman, T. R. (1967): "Categorisation Behaviour and Achievement in Deaf and Hearing Children." Exceptional Children. 34, 4, pp. 241-250.

20. Strauss, A. A. and Kephart, N. C. (1955): Psychopathology and Education of the Brain-Injured Child. Grune \& Stratton, New York.

21. Strauss, A. A. and Lehtinen, L. (1947): Psychopathology and Education of the Brain-Injured Child. Grune \& Stratton, New York.

22. Vygotsky, L. S. (1962): Thought and Langinage. M.I.T. Press. 